\title{
Usuários da informação, tecnologia e educação
}

\author{
Users of the information, technology and education
}

Marco Antônio de ALMEIDA'

Tatiana Bocardo AITA2

\section{RESUMO}

O artigo analisa os perfis de usuários no ciberespaço. Por meio de questionários e entrevistas qualitativas realizadas com alunos da USP em Ribeirão Preto, foram levantados dados para refletir sobre o tema. Esse mapeamento trouxe subsídios para melhor avaliar os instrumentos de pesquisa e de organização da informação disponíveis. $\bigcirc$ trabalho utilizou instrumentos de pesquisa e formas de análise que consideraram aspectos quantitativos e qualitativos. O objetivo foi conhecer melhor os mecanismos de interação entre os usuários e os sistemas informacionais, obtendo subsídios para avaliar os processos de formação em curso na universidade e sua relação com as novas tecnologias de comunicação e informação. Foi observado como as atividades de mediação e formação dos usuários para a informação são estratégicas para a obtenção de bons resultados.

Palavras-chave: informação; usuários; educação; tecnologia; mediação.

\begin{abstract}
The article analyzes the profiles of users in cyberspace. Through questionnaires and qualitative interviews conducted with students from USP in Ribeirão Preto, data were collected to reflect on the theme. This mapping has brought benefits to better evaluate the research and organization of information tools available. The study used research instruments and forms of analysis that considered the quantitative and qualitative aspects. The objective was to better understand the mechanisms of interaction between users and information systems, obtaining subsidies to assess the processes of training course at the university and its relationship with the new technologies of communication and information. Was observed as the activities of mediation and training of users to the information are strategic to achieving good results.
\end{abstract}

Keywords: information; users; education; technology; mediation.

\section{INTRODUÇÃO}

O usuário super-esperto é o fim do profissional da informação?
Uma parcela razoável dos leitores deste texto já deve ter assistido a um vídeo de sucesso no YouTube intitulado "Rafinha 2.0" (disponível em: http:// www.youtube.com $/$ watch? $v=U 12 \mathrm{~m} 5 \mathrm{knV}$ rvg). Nesse

\footnotetext{
1 Doutor em Ciências Sociais. Professor do PPGCI/ECA-USP e do curso de Ciências da Informação e Documentação da FFCLRP-USP. Correspondência para/Correspondence to: M.A. ALMEIDA. E-mail: <marcoaa@ffclrp.usp.br>.

2 Bacharel em Biblioteconomia e Ciência da Informação/ FFCLRP-USP.

Recebido em 8/7/2009 e aceito para publicação em: 30/9/2009.
} 
vídeo somos apresentados ao Rafinha, adolescente que seria um típico representante da geração $\mathrm{C}$ - a geração do conteúdo, da colaboração e da conexão. Rafinha já possui habilidades de edição de imagem, texto e áudio extremamente desenvolvidas, que utiliza nesse universo de "informação fácil", de variedade de escolhas, onde a relação entre empresas, clientes e consumidores de todas as faixas etárias é muito mais próxima do que jamais foi. Plenamente adaptado ao universo da WEB, Rafinha se desloca autonomamente pela rede, sem necessitar do auxílio de mediadores ou profissionais da informação.

Mas será que as coisas funcionam dessa maneira, tão perfeita, para todos?

Os aspectos socioculturais e os impactos decorrentes da expansão cada vez maior da internet têm sido apontados por diversos autores, com avaliações que oscilam entre o entusiasmo e a crítica com nuances apocalípticas (Castells, 2003; Lévy, 1999; Wolton, 2003) Castells chama a atenção para a alternativa proporcionada pela internet no que tange ao desenvolvimento de projetos individuais e coletivos nas sociedades contemporâneas, que encontram na rede a possibilidade de uma extensão dos limites físicos do cotidiano, gerando canais de comunicação, comunidades e redes de afinidades. São múltiplas as formas encontradas na Internet que possibilitam a comunicação interpessoal, o trabalho colaborativo e o acesso às informações. Do e-mail aos sites, passando pelos chats e pelos blogs, a Internet é um amplo arsenal de possibilidades. $\bigcirc$ êxito dessas comunidades virtuais, entretanto, estaria relacionado para ele ao fato delas estarem voltadas para a execução de tarefas ou perseguir interesses comuns (Castells, 2003). Constróise, assim, no espaço virtual, uma comunidade de indivíduos com interesses comuns. Por outro lado, ele também chama a atenção para as diferenças e hierarquizações sociais que também persistem nesse ambiente. No caso especificamente das crianças e dos jovens, mais importante que a conectividade técnica é a capacidade de utilizar a internet diretamente relacionada à cultura e à educação:

Uma vez que toda a informação está na rede ou seja, o conhecimento codificado, mas não aquele de que se necessita -, trata-se antes de saber onde está a informação, como buscá-la, transformá-la em conhecimento específico para fazer aquilo que se quer fazer. Essa capacidade de aprender a aprender; essa capacidade de saber o que fazer com o que se aprende; essa capacidade é socialmente desigual e está ligada à origem social, à origem familiar, ao nível cultural, ao nível de educação. É aí que está, empiricamente falando, a divisória digital nesse momento. (CASTELLS, 2003, p.266)

Se de um lado é obvia a existência de garotos e garotas como Rafinha, por outro lado também é óbvio que eles não sejam, talvez, exemplares da maioria de indivíduos conectados à internet - que dizer, então, daqueles que nem conectados estão? Como interagir, ou pelo menos tentar compreender as necessidades dos milhões de internautas que se aventuram pelo ciberespaço sem as habilidades de Rafinha?

Em geral é relativamente fácil avaliar o uso real que é feito dos produtos e serviços de informação oferecidos por uma unidade de informação; entretanto, é muito mais difícil avaliar as necessidades dos usuários, pois muitas delas nem chegam a ser percebidas por ele. Muitas vezes o usuário só reconhece uma necessidade de informação quando os meios para satisfazê-la estão acessíveis. De um modo geral, a área de Ciência da Informação voltou-se para essa realidade dos usuários combinando pesquisa com desenvolvimento de produtos informacionais.

No caso específico desse trabalho, o foco principal foi traçar um perfil de usuário de informação dos alunos do curso de Ciências da Informação e Documentação (CID) da Faculdade de Filosofia, Ciências e Letras de Ribeirão Preto (FFCLRP-USP). De um modo geral, são pessoas de uma geração e ambientes culturais muito próximos do que seria $o$ universo de Rafinha. Esse mapeamento pode trazer dados para melhor avaliar os instrumentos de busca de pesquisa e organização da informação existentes, analisando-os nos aspectos quantitativos e qualitativos, trazendo subsídios que possibilitem o aprimoramento ou eventual substituição por outros mais adequados. $\bigcirc$ que se busca, além de conhecer melhor os mecanismos de interação entre os usuários e os sistemas informacionais, são elementos para avaliar os processos de formação em curso na universidade e sua relação com as novas tecnologias de comunicação e informação. Nesse sentido, esperamos apontar como as atividades de mediação e formação dos usuários para a informação são estratégicas para a obtenção de bons resultados. 
Do ponto de vista da metodologia aplicada, desenvolvemos a pesquisa em duas etapas sucessivas e complementares.

Na primeira etapa, mapeamento inicial e análise das necessidades informacionais e tecnológicas dos alunos do curso do CID, foram selecionados recursos para comunicação na internet supostamente utilizados pelos alunos e professores como meio de interação e busca por informações referentes ao ambiente acadêmico. Compuseram a seleção sites e blogs oferecidos pela universidade como o próprio site da FFCLRP-USP e o STOA (site de rede social dos estudantes, professores e funcionários da Universidade de São Paulo) e sites, blogs e grupo de e-mails disponíveis na internet para qualquer usuário, como o Yahoo!Grupos, o site de relacionamento Orkut (que oferece variadas comunidades relacionadas aos cursos da FFCLRP-USP) e o TELEDUC (site utilizado para a criação de cursos na web). Nesta pesquisa exploratória foi feita a descrição dos espaços utilizados pelos alunos da faculdade, com o objetivo de mapear suas funções e interfaces, ou seja, mostrando o que o usuário encontra quando os acessa. A partir dessa seleção, realizamos um processo de análise centrado nas vantagens e problemas de navegação que podem ser encontrados durante o acesso a esses sistemas, além de observar como isso poderia influenciar o processo de busca por informações e interatividade entre os usuários. Por último, concentramo-nos no perfil dos usuários, aplicando aos alunos do CID um questionário com o objetivo de coletar dados mais detalhados, em especial quais seriam os sistemas informacionais mais utilizados por eles, o que eles procuram nestes sistemas, além de críticas e sugestões durante o uso dos mesmos.

Na segunda etapa da pesquisa partimos do perfil preliminar dos usuários/alunos obtido na fase anterior, e passamos a privilegiar uma abordagem mais qualitativa dos dados, buscando conhecer melhor a atuação desses usuários/alunos no ciberespaço e o perfil daí decorrente. Esta fase da pesquisa estruturouse como uma entrevista-observação participativa, seguindo uma sugestão proveniente de Lucia Santaella (2004), envolvendo observação e entrevistas participativas com uma amostra selecionada de usuários, aos quais são propostas algumas tarefas no ciberespaço. $\bigcirc$ sistema escolhido como alicerce para as entrevistas foi o STOA. Inicialmente trabalhamos com uma amostra de oito entrevistas, mas apenas sete foram consideradas no resultado final. Para a realização das entrevistas, alguns critérios foram adotados (ter computador próprio ou acesso constante a um fora da universidade; saber navegar na rede e possuir algum grau de familiaridade com ferramentas de compartilhamento e busca de informações como o Google ou grupos de e-mail).

\section{PRIMEIRA ETAPA: MAPEANDO O CIBERESPAÇO}

Primeiro site a ser analisado foi o da própria Faculdade de Filosofia, Ciências e Letras de Ribeirão Preto, pertencente à Universidade de São Paulo, encontrado no endereço http://www.ffclrp.usp.br, já que nele estão expostas várias informações sobre os cursos, departamentos, bolsas de pesquisa, funcionários e outras utilidades para os usuários. Ao acessar a página inicial do site, o usuário irá encontrar vários ícones à esquerda da página, que contêm informações de interesses múltiplos à respeito da faculdade. No ícone "A FFCLRP", o usuário tem acesso a subcampos que contêm informações sobre o histórico, a localização, a direção, colegiados e administração da faculdade. Nestes subcampos os usuários vão possuir informações desde o histórico da faculdade até informações sobre nomes de diretores e ex-diretores, assessorias e suas funções e e-mails para contato. Outros ícones, onde o usuário pode ter acesso a outros tipos de informações são: "Departamentos", onde se encontram informações sobre os docentes, funcionários, cursos de graduação, atividades de extensão e centros de pesquisa existentes; "Graduação" e "Pós-graduação", ícone que expõe históricos, informações sobre a secretaria, sobre transferências, informações acadêmicas, calendário escolar e contatos; "Editais" e "Licitações", ícones onde são postados os editais de concursos e processos seletivos; "Links importantes", ícone onde o usuário poderá visitar vários outros órgãos ligados à Universidade de São Paulo; e por ultimo "Agremiações", ícone que contêm as descrições dos centros estudantis da FFCLRP-USP e e-mails para contato.

Outro espaço mapeado foi o STOA, que se encontra no endereço http://stoa.usp.br. O STOA é uma rede social dos estudantes, professores e funcionários da Universidade de São Paulo, e tem como objetivo promover uma maior interação entre os membros da comunidade USP, criando um espaço onde cada pessoa dentro da universidade tenha uma 
identidade digital de fácil acesso, além de fornecer um sistema software que facilite aos professores a administração de seus cursos para os estudantes. Para ter acesso a este recurso é necessário ser estudante, professor ou funcionário da USP.

Ao acessar o STOA, o usuário visualiza o menu principal, que é dividido em ícones como: "Seu perfil", campo em que se pode fazer uma descrição detalhada pessoal e acadêmica do usuário, como por exemplo, expor fotos, fazer uma breve descrição de quem ele é, demonstrar quais são seus interesses, do que gosta ou não, falar de suas habilidades, informar detalhadamente onde mora (cidade, bairro, rua, CEP, etc.), expor contatos (telefone residencial, comercial e celular, email, msn, etc.), detalhar quais disciplinas cursa, qual faculdade, instituto e/ou departamento pertence, e ainda exibir seu currículo Lattes (onde descreve o que já realizou na jornada acadêmica). O ícone "Seu Blog (Arquivo)", possibilita o usuário criar seu weblog, onde o usuário pode fazer postagens, ver seus arquivos, navegar nos blogs dos seus contatos, e ver mensagens. Este ícone oferece também recursos para a seleção de conteúdos que sejam importantes para o usuário. Outros ícones disponibilizados pelo STOA são: "Apresentações", ícone que proporciona ao usuário a criação de títulos, palavras-chave para a identificação de suas mensagens; "Calendário", oferece ao usuário uma agenda virtual para compromissos; "Arquivos", dá ao navegante a possibilidade de enviar e buscar arquivos; "Agregador", disponibiliza a possibilidade de acesso à outros links relacionados à conteúdos postados por outros usuários; "Sua atividade", neste campo o usuário pode verificar quais foram suas atividades durante os períodos de 24 horas, 48 horas, uma semana e um mês; e por último um dos ícones que mais oferece integração e troca de conhecimento dentro do sistema, o "Wiki", ícone que oferece ao usuário a possibilidade de acessar e participar de fóruns de discussão, acesso à artigos, e diversos blogs interessantes às necessidades dos usuários.

Como já mencionado acima, no decorrer da seleção dos recursos de comunicação via internet, supostamente, mais utilizados pelos alunos incluí-se também sites, blogs e e-mails que não são oferecidos pela Universidade de São Paulo, mas são de uso freqüente pelos alunos na universidade. Um exemplo é - TELEDUC, que pode ser visitado no endereço hHtp:// arenito.cirp.usp.br/ TELEDUC. O TELEDUC tem como principal função auxiliar o ensino-aprendizagem à distância, permitindo criar, participar e administrar cursos através da internet, configurando-a como forma de auxilio para as disciplinas ministradas nas universidades. Dessa forma, quando o usuário acessa o site do projeto, ele encontra opções para navegar de maneira fácil para encontrar o curso desejado, utilizando as opções "cursos em andamento", onde se encontram os cursos ministrados no atual semestre; "cursos com inscrições abertas"; "cursos já oferecidos", com uma listagem de todos os cursos; e por fim a opção "como criar um curso", uso permitido somente por professores, funcionários ou alunos participantes de projetos de pesquisa.

Depois de escolhido o curso desejado, e após já estar devidamente matriculado e autorizado pelo criador do curso, o usuário terá acesso a vários ícones, como por exemplo, "material de apoio", opção que oferece materiais para auxilio ao usuário durante o andamento do curso, como leituras, apresentações em power point, dentre outros. $O$ usuário também pode contar com o acesso a fóruns de discussão (onde assuntos debatidos em aula e questionamentos sobre as leituras podem ser discutidos e trabalhados pelos usuários), obter auxilio na entrega de trabalhos (onde o aluno posta seu trabalho em pasta compartilhada) e na formação de grupos para seminários e outras atividades.

Outros recursos de comunicação virtual visitados, que não são oferecidos pela universidade foram o site de relacionamentos Orkut e o Yahoo! Grupos, ambos encontrados nos respectivos endereços www.orkut.com e http://br.groups.yahoo.com. No Orkut, analisamos o relacionamento dos alunos nas comunidades destinadas aos cursos da FFCLRP-USP, onde os mesmos além de debaterem sobre diversos temas relacionados ao meio acadêmico, abrem espaço para outros assuntos de interesse comum, mesmo que não sejam ligados à universidade. Essas comunidades são compostas por nome, descrição sobre o propósito de sua criação e oferecem espaços para pesquisas de opinião (enquête) e para divulgação de eventos. As comunidades também dão ao usuário a oportunidade de participar de fóruns de discussão, compartilhando com outros usuários assuntos de seu interesse e até mesmo criando convívios reais. Não se trata de entrar em um ambiente fechado onde questões e respostas já estão "pré-questionadas" e "pré-respondidas". Trata-se de uma interface onde 
questões podem ser colocadas e onde as respostas podem ser construídas, mesmo sem as perguntas e soluções terem sido previstas. Já no Yahoo!Grupos, que é um serviço que permite reunir pessoas por meio de um Website e grupos de e-mail, o usuário pode encontrar uma forma de conectar-se com outras pessoas que compartilham os mesmos interesses e idéias, além de poder criar grupos de e-mail, nos quais outros usuários podem se escrever e utilizar o serviço através de um programa de e-mail. Em ambos os casos, os usuários estão livres para discutir sobre assuntos de interesses de seus cursos de graduação, vagas de estágio informações sobre as aulas e demais assuntos. Porém esses sistemas contam com uma opção de moderação e podem sofrer interferências do seu criador.

A partir dessas descrições pudemos analisar a presença de sistemas reativos e mútuos, ou até ambos os sistemas no mesmo recurso de comunicação virtual. Segundo Primo, as interfaces potenciais reativas desenham e calculam uma rede, onde estímulos e respostas já se encontram definidos e encadeados mesmo antes da chegada do usuário. Geralmente, a interface potencial é um exemplo usado em sistemas tradicionais de ensino por serem lineares e mecanicistas. Existe um outro ambiente, onde há uma interação entre os usuários, que pode ser considerado como um sistema mútuo de interface virtual, onde o usuário tem a possibilidade de interagir com outros usuários, compartilhando de interesses e opiniões comuns e até mesmo criando convívios reais. Nesses ambientes se permite uma mútua construção. Na interface virtual cada interagente pode transformar e criar seus percursos. Trata-se de uma interface onde questões podem ser colocadas e onde as respostas podem ser construídas (Primo, 2007).

Vemos, por exemplo, que o site da FFCLRP e o TELEDUC reproduzem a apresentação de informações previamente estruturadas e restritas a determinadas respostas, assim o usuário está pronto para receber o conhecimento transmitido. Nessa relação reativa não há interação, tendo em vista que ela é determinada e de pouca liberdade criativa. Mas ao analisar a opção "fórum de discussão" no TELEDUC, notamos um sistema mútuo, onde o interagente pró-ativo estimula a interação entre os usuários através do debate de um tema por ele definido e é nesse ponto que se criam as relações: os usuários se manifestam expressando suas opiniões sobre o tema em questão discordando e concordando uns com os outros até que se chegue, ou não, a um consenso.

Os demais recursos analisados apresentam essencialmente um sistema mútuo, mas esbarram na opção de moderação existente nesses recursos. Muitos desses recursos passam a ser fechados e moderados pelo seu criador ou interagente pró-ativo, o que faz com que os caracterizemos como sistemas, em partes, reativos.

Considerando as ferramentas selecionadas e descritas anteriormente, analisamos algumas das vantagens e problemas de navegação encontrados durante o acesso a esses sistemas, observando como isso afetaria o processo de busca por informações e interatividade entre os usuários. Iniciamos a análise pelos sites oferecidos pela universidade (USP). $\bigcirc$ site da FFCLRP-USP, como dito anteriormente, é dividido em sessões representadas por ícones, onde o usuário poderá encontrar informações sobre a faculdade e o campus da USP de Ribeirão Preto. $\bigcirc$ site conta com uma interface bem estruturada, onde as sessões são de fácil navegação, com conteúdo bem explicitado, facilitando ao usuário localizar as informações que deseja, porém durante a análise para descrição do site, encontramos um problema relacionado à sessão "Agremiações". Através dela, obtivemos contato com os alunos dos centros acadêmicos para realizarmos a pesquisa sobre quais os meios de comunicação na Internet são utilizados pelos alunos como forma de interação e busca por informações relacionadas ao meio acadêmico, no entanto, muito dos e-mails para contato que estão registrados no site se encontram desatualizados (o que causou certo atraso na obtenção das informações necessárias, obtidas por meio de contatos informais com alunos dos cursos).

Analisando o STOA, nos deparamos com um sistema mútuo, em que os usuários podem facilmente trocar e buscar conhecimentos, além de expor suas idéias e opiniões a uma rede social virtual oferecida pela Universidade de São Paulo. As principais vantagens encontradas neste recurso são: a grande possibilidade de comunicação entre os usuários, dando ênfase aos variados blogs criados pelos participantes, de diversificados assuntos acadêmicos e interesses comuns; as indicações de links sobre conhecimentos compartilhados pelos usuários e a acessibilidade a artigos postados e/ou criados pelos próprios usuários. O STOA possui assim como o site da FFCLRP-USP uma 
boa interface que facilita o acesso dos usuários em alguns ícones, no entanto um dos problemas encontrados foi a não clareza de alguns recursos oferecidos (como a busca por comunidades, assunto discutido mais adiante), o que dificulta a navegação do usuário no sistema. Outro problema detectado, e talvez o maior deles, é a falta de divulgação deste recurso junto aos alunos, professores e funcionários da Universidade.

Dando continuidade à pesquisa, realizamos a mesma análise no TELEDUC, e constatamos que, por ser um sistema reativo, a partir do momento que o usuário acessa um dos cursos - que obviamente esta matriculado, pois o mesmo necessitará de um login e uma senha para o acesso - ele entrará em uma interface onde seus "caminhos" estarão pré-definidos, ou seja, o usuário irá navegar pelas sessões e pelos ambientes do site e tudo o que encontrar será relativo ao propósito do curso, e o único modo de seguir por outros caminhos da grande teia de comunicação que é a web, é fazer o "caminho" de volta. Por outro lado, o usuário conta com uma interface de fácil navegação, com sessões bem definidas, além da opção "fórum de discussão", exemplo de sistema mútuo, citado anteriormente, onde poderá interagir com outros usuários.

Por fim analisamos o site de relacionamentos pessoais Orkut e o serviço Yahoo! Grupos. Os dois serviços apresentam semelhanças, pois são sistemas mútuos de interfaces virtuais, e possibilitam total interatividade entre seus usuários. O Orkut conta com uma interface gráfica de fácil navegação, onde o usuário está livre para explorar perfis de outros usuários e contatá-los, além de ter a sua disposição uma série de comunidades de temas variados. Dentre essas comunidades, está a relacionada ao CID da USP Ribeirão Preto, onde nossa pesquisa concentrou-se. Apesar destas vantagens, salientamos o fato de que por ser um ambiente virtual, onde o acesso é livre, o número de usuários é vasto, o que torna difícil o controle
- conseqüentemente a demanda de informações também é livre, e por mais que estejamos falando da comunidade relacionada ao CID, o número de informações na maioria das vezes não provém de fontes confiáveis. Por outro lado, apesar do serviço Yahoo! Grupos também possuir uma interface virtual, proporcionando a interatividade entre os seus usuários, ele conta com um sistema de moderação que controla a entrada e saída de membros, e por ser um serviço utilizado por um número menor de pessoas, o controle da informação vinculada no grupo e o de usuários cadastrados é facilitado.

Após o mapeamento acima, em que procuramos analisar as estruturas e interface dos sistemas informacionais na Internet, concentramo-nos no perfil de seus usuários. Elaboramos um questionário com o objetivo de coletar dados mais detalhados, em especial quais seriam os sistemas informacionais mais utilizados por estes usuários, o que eles procuram nestes sistemas, além de críticas e sugestões durante o uso dos mesmos.

Os questionários foram aplicados no dia 25 de outubro de 2007, durante a IV Semana de Estudos em Ciência da Informação da Faculdade de Filosofia, Ciências e Letras de Ribeirão Preto. Durante o evento os questionários foram distribuídos aos alunos, que responderam anonimamente e o devolveram ao final do encontro. O questionário possuía oito questões, sendo seis de múltipla escolha e duas dissertativas. As questões buscavam saber dos alunos se eles utilizavam sistemas informacionais da Internet para a interação e busca por informações relacionadas ao meio acadêmico; se esses sistemas eram fornecidos pela Universidade ou se eles utilizavam outros sistemas; qual a freqüência com que acessavam esses sistemas; quando era necessário o acesso, além de críticas relacionadas aos problemas encontrados durante a navegação e sugestões para uma melhoria desses sistemas. Depois da aplicação, recolhemos trinta e nove questionários respondidos durante o evento e obtivemos os seguintes resultados:

Tabela 1. Uso de Sistemas Informacionais na Internet.

\begin{tabular}{|c|c|c|c|}
\hline Questão & Sim & Não & $\begin{array}{l}\text { Não } \\
\text { respondeu }\end{array}$ \\
\hline Utiliza sites acadêmicos disponibilizados pela universidade? & $82 \%$ & $15 \%$ & $3 \%$ \\
\hline $\begin{array}{l}\text { Fez uso de algum sistema virtual que auxiliasse no desenvolvimento de disciplinas } \\
\text { cursadas na Universidade? }\end{array}$ & $95 \%$ & $5 \%$ & \\
\hline $\begin{array}{l}\text { As ferramentas virtuais são um meio prático para trocas de informações e conheci- } \\
\text { mentos acadêmicos? }\end{array}$ & $87 \%$ & $8 \%$ & $5 \%$ \\
\hline
\end{tabular}


Uma outra questão buscou levantar com qual freqüência o aluno utiliza grupos de discussão na internet (e-mail, blogs e/ou comunidades virtuais) e se utiliza, quais são eles. Observamos que $44 \%$ responderam que participam "intensamente" de grupos de discussão, 26\% responderam que participam "freqüentemente", 15\% responderam que participam "raramente" e 15\% disseram "não utilizar" nenhum desses sistemas. Entre os sistemas mais citados pelos alunos estão o Yahoo!Grupos, TELEDUC, STOA, blogs e comunidades do Orkut. Além disso, também observamos que $72 \%$ afirmaram encontrar a "maioria" das informações que procuram, enquanto 18\% disseram encontrar "poucas" informações e 5\% "raramente" encontram informações (os outros $5 \%$ não opinaram). Finalmente, procuramos saber como os alunos classificavam a utilização das ferramentas virtuais oferecidas pela Universidade: 41\% responderam que essas ferramentas são "essenciais" para a aquisição e troca de informações de interesses comuns, 51\% responderam que são "complementares" para a aquisição de conhecimentos, enquanto 5\% eram "indiferentes" (3\% não opinaram).

Nas questões dissertativas, perguntamos inicialmente aos alunos quando era necessário fazer uso de sites, grupos de discussão, blogs, etc. oferecidos no ambiente universitário. De um modo geral, os alunos pesquisados responderam que fazem uso desses sistemas quando necessitam complementar os conhecimentos adquiridos em sala de aula, além de utilizarem para pesquisas acadêmicas e troca de informações com outros alunos. A outra questão pedia que fossem apontados alguns problemas geralmente encontrados durante o uso dessas ferramentas. Entre os mais citados, estavam: o excesso de informações, que dificultam as buscas; a restrições ao acesso de determinadas informações; problemas na estrutura dos sites, dificultando a navegação e problemas relacionados às bases de dados que são disponíveis somente dentro do ambiente da Universidade, por serem pagas.

Tomando por base os resultados dos questionários e levando em conta os perfis dos sistemas informacionais estudados, podemos chegar a algumas conclusões.

Depois dessa análise, percebemos que a utilização desses sistemas é importante para o auxilio às atividades acadêmicas. A maioria dos alunos pesquisados utiliza intensamente essas ferramentas como forma de complemento às atividades em sala de aula, além de troca de informações e como forma de interação, como por exemplo, interações aluno/aluno e aluno/docentes. Porém, como o fluxo de informações na Internet é muito grande, vários alunos afirmaram apresentar dificuldades para localizar as informações que realmente são relevantes. Além disso, algumas ferramentas apresentam uma interface com excesso de detalhes, o que dificulta sua compreensão e não permite a adaptação das ferramentas às necessidades do usuário.

\section{SEGUNDA ETAPA: NAVEGANDO COM OS USUÁRIOS}

Com base nesse perfil preliminar, partimos para a realização das entrevistas em profundidade com os alunos. Selecionamos inicialmente oito usuários para as entrevistas, mas uma delas foi eliminada por inconsistência e apenas sete foram consideradas no resultado final. Para a realização das entrevistas adotamos como critérios: possuir computador próprio ou acesso constante a um fora da universidade; saber navegar na rede e possuir algum conhecimento mínimo de ferramentas de compartilhamento e busca de informações como o Google ou grupos de e-mail. $\bigcirc$ sistema-base escolhido como referência para as entrevistas foi o STOA. A entrevista foi estruturada em três blocos, todos baseados nos dados já coletados na primeira amostra de usuários que responderam ao questionário.

primeiro bloco foi uma entrevista informal, visando conhecer melhor os usuários que iríamos estudar. Como $82 \%$ dos alunos pesquisados responderam nos questionários que faziam uso de sistemas fornecidos pela universidade para interação e busca por informações, perguntamos se o aluno conhecia o sistema STOA, para podermos analisar qual o nível de conhecimento que os alunos dispunham sobre esse sistema e como o mesmo foi divulgado entre os alunos. Em resposta, todos os entrevistados declararão conhecer o STOA através de uma disciplina oferecida no curso, mas após o termino da disciplina, seis mantiveram seus perfis inativos e apenas um dos entrevistados ainda fazia uso da ferramenta em seu cotidiano. Os alunos também deram suas opiniões iniciais sobre a ferramenta, explicitando que a falta de divulgação da mesma entre os alunos era o maior problema para sua utilização na graduação e que uma 
maior divulgação por parte dos professores ajudaria de forma substancial uma maior utilização da ferramenta pelos alunos do curso. Outro ponto destacado foi que, em sua maioria, os alunos acham o STOA uma boa ferramenta de compartilhamento de informação, onde os graduandos poderiam trocar informações com professores e alunos de outras áreas, destacando a possibilidade de utilizá-lo como suporte para as aulas ministradas na universidade, mas sem deixar de ressaltar que a interface pode até ser visualmente bonita, mas a sua utilização é confusa. Ou seja, todos os entrevistados declararam que a interface do STOA não facilita a utilização do usuário.

Outra questão para análise é o quanto é importante para o aluno a utilização de recursos como - STOA (ou outro sistema que o aluno tenha utilizado), no auxílio ao estudo, a pesquisa e/ou nas disciplinas cursadas. Procuramos, portanto, observar o nível de facilidade/dificuldade no acesso e navegação dessas ferramentas, bem como o nível de satisfação informacional durante sua utilização, verificando como esse tipo de ensino a distância poderia ser substancial na formação dos alunos. Em resposta, os alunos destacaram que o sistema tem muito potencial para aprimorar e auxiliar os estudos acadêmicos, mas deixaram claro que sua interface e sua divulgação são deficitárias, o que prejudica a utilização e os propósitos do projeto STOA. Nas respostas também verificamos sugestões e críticas como as que seguem abaixo:

- A divulgação do STOA deveria ser feita para os alunos assim que eles ingressam na USP, pois assim já estariam aptos a utilizar a ferramenta nas disciplinas do curso.

- A busca por arquivos pode ser mais eficiente dentro da ferramenta do que na rede em geral, iá que os arquivos são postados pelas pessoas da própria universidade.

- Grande possibilidade de armazenar arquivos dentro do perfil do STOA e ainda destaque para a possibilidade de realizar trabalhos em conjunto, como artigos e organização de eventos.

Na continuação do processo de entrevistas, passamos para o segundo bloco dessa etapa da pesquisa, onde dividimos os alunos em dois grupos: 0 grupo um, onde os alunos possuíam familiaridade com - STOA, e o grupo dois, onde os alunos não tinham familiaridade com o sistema em questão. Dos sete entrevistados, dois se encaixavam no grupo um e cinco no grupo dois. Isso mostra que mesmo que todos os entrevistados já fossem cadastrados e utilizassem o sistema, as dificuldades de navegação e a falta de divulgação da ferramenta foram grandes empecilhos para a permanência destes usuários no sistema STOA. Vale observar que, mesmo os alunos que se encaixavam no grupo um, apresentaram dificuldades, não aproveitando de maneira plena a ferramenta, como veremos mais adiante. Esta fase da pesquisa constou de uma entrevista-observação participativa, seguindo uma abordagem presente em Lucia Santaella (2004), envolvendo observação e entrevistas participativas com uma amostra selecionada de usuários, aos quais são propostas algumas tarefas no ciberespaço.

A primeira tarefa utilizando o sistema STOA propunha que os entrevistados se cadastrassem no sistema e preenchessem seus respectivos perfis, mas os sete entrevistados já eram cadastrados e tinham as informações básicas no perfil. Desse modo, passamos para a segunda proposta, que demandava dos alunos procurar a comunidade do curso de Ciências da Informação e Documentação da USP Ribeirão Preto, intitulada CID, ou outra comunidade de seu interesse e ingressar como membro dessa comunidade. Dos sete entrevistados, três não tiveram grandes dificuldades em cumprir a tarefa, visto que possuíam alguns conhecimentos da ferramenta obtidos em navegações anteriores. Os quatro entrevistados restantes tiveram muita dificuldade de localizar comunidades dentro do STOA, apresentando grande confusão durante a navegação, "indo e voltando" pelas páginas do sistema, muitas vezes necessitando do auxilio do entrevistador para dar andamento à navegação.

Com a análise do que aconteceu durante a navegação e com os elementos obtidos por meio das entrevistas participativas, é possível fazer algumas observações sobre os usuários pesquisados e sobre o sistema STOA.

Podemos observar que, em sua maioria, os alunos do curso em questão não têm o hábito de utilizar ferramentas de interatividade virtual, ou seja, os graduandos só fazem uso destes tipos de sistemas quando obrigados por alguma disciplina da grade curricular. Desse modo, é possível inferir que o incentivo por parte dos professores e a maior divulgação destes sistemas pela universidade poderiam modificar este quadro. Isto também é observado nas críticas da 
entrevista informal, onde os alunos sugerem que os professores utilizem mais estes sistemas interativos, principalmente o STOA, em suas disciplinas, e que a USP divulgue e melhore o mesmo para sua utilização em massa entre os membros da universidade. Como observa Roseliy Zen Cerny no livro A formação da sociedade do espetáculo, nos tempos atuais os educadores devem repensar os conceitos de educação e aprendizagem, tanto nos métodos didáticos quanto nos meios materiais:

A educação com características autoritárias, nãodialógicas, na qual o aluno passivamente assimila os conteúdos transmitidos pelo professor, precisa definitivamente ser superada, pois já não atende às necessidades de formação do sujeito de hoje. Cabe aos educadores sensibilizarem-se com essa realidade e incorporarem alternativas de aprendizagem que tenham em sua base o processo de comunicação mediado pela tecnologia, integrando os dois sistemas: presencial e a distância. (Cerny, 2002, p. 165)

Diante do exposto, podemos considerar que o STOA possui uma deficiência na busca por comunidades dentro do seu sistema - deficiência passível de ser superada, visto que o STOA é uma ferramenta em construção e acolhe sugestões e conhecimentos dos seus próprios usuários para a melhoria do sistema. As sugestões e críticas podem ser demonstradas via e-mail (suporte@STOA.usp.br),na comunidade de suporte, ou em várias comunidades criadas para a discussão no interior do próprio sistema, como a comunidade "ESPAÇO USP".

$\mathrm{Na}$ continuação da entrevista-observação participativa, foi proposta uma terceira tarefa de navegação: postar comentários no fórum de discussão da comunidade acessada anteriormente ou qualquer comunidade de sua escolha. Cinco alunos postaram seus comentários na comunidade proposta sem dificuldade, pois entraram na mesma e clicaram no ícone "fórum (histórico)", do lado direto da tela. Depois escolheram o tópico de seu interesse, leram os comentários e deixaram suas considerações. Os dois alunos restantes se diferenciaram dos demais, pois um criou um novo fórum (novo post) em uma comunidade de interesse pessoal, visto que a mesma ainda não possuía tópicos para discussão. $\bigcirc$ outro entrevistado teve maiores dificuldades para achar o fórum da comunidade e postar o comentário, necessitando do auxilio do entrevistador.
A quarta e última proposta demandava que os alunos pesquisassem determinados arquivos, como artigos compartilhados entre os usuários do STOA. Essa busca poderia ser feita de duas formas: a - por meio do WIKI do próprio STOA ou b - por meio do Google, site ao qual o STOA é vinculado. Alguns arquivos de um aluno do próprio curso foram oferecidos como objetivos para a busca. Quatro dos entrevistados utilizaram o WIKI do STOA para executar a tarefa, enquanto os outros três utilizaram o campo de busca do lado direito da tela, filtrado pelo Google, para realizar a busca. Mesmo que os sete entrevistados tenham realizado a busca por arquivos com sucesso, quatro apresentaram dificuldades para iniciar os procedimentos necessários, ou seja, esses alunos navegaram em vários ícones no sistema antes de localizar onde poderiam fazer a busca dos arquivos.

Depois de terminada a fase das tarefas, realizamos mais um bloco de perguntas aos entrevistados sobre o que eles acharam do sistema STOA e se teriam algumas sugestões para a melhoria desta ferramenta. Além das sugestões já expostas nas outras etapas das entrevistas, os alunos também propuseram: a - uma categorização dos trabalhos (trabalhos de graduandos, doutores, artigos, etc.), para assim confirmar a confiabilidade do que está postado; b-um melhoramento do filtro de buscas; c-um treinamento sobre como utilizar o STOA direcionado para os professores e para os alunos.

Em síntese, o que mais se destacou nas críticas ao sistema é, de um lado, a interface confusa, principalmente na busca de comunidades e de arquivos, e de outro, a falta de divulgação entre os alunos, professores e funcionários da instituição. As sugestões de melhoria mais citadas confirmam esse diagnóstico: são cursos de como utilizar o STOA, maior divulgação do sistema por parte dos professores e utilização da ferramenta nas disciplinas oferecidas no curso, como um meio de interação, auxilio e aprofundamento dos conhecimentos apresentados em sala de aula pelos docentes.

Embora os alunos do curso de Ciências da Informação e Documentação não utilizem geralmente essa ferramenta, eles fazem uso de outras não oferecidas pela Universidade de São Paulo, entre elas o Yahoo!Grupos e uma comunidade no site de relacionamentos Orkut. A partir de uma monitoração no Yahoo!Grupos foi possível verificar quais são os 
tipos de informações e necessidades que os alunos demonstraram ter neste meio virtual.

Yahoo!Grupos possui como moderadores alunos do próprio curso, mas durante o monitoramento podemos observar que o moderador não exercia o seu papel de filtrar e classificar as informações disponibilizadas pelos participantes do grupo de e-mail. A maior parte das informações que circulam neste grupo pode ser classificada de duas maneiras. Em primeiro lugar, as informações acadêmicas, ou seja, aquelas vinculadas às disciplinas cursadas ou ao crescimento científico e profissional dos alunos, como por exemplo, textos das aulas ministradas, informações sobre vagas de estágio e/ou bolsas de pesquisa cientifica. E, em segundo lugar, as informações de cunho cultural, colaborativo e assuntos pessoais.

Mediante a divisão dos tipos de informação disponíveis no grupo de e-mail, atestamos que o mesmo não sofre nenhum tipo de interferência dos moderadores, pois as informações não são filtradas, causando um grande incômodo aos integrantes do grupo, que se deparam com suas caixas de e-mail cheias, mas com poucas informações realmente pertinentes aos seus interesses em geral. Isto pode ser observado também em e-mails de integrantes do grupo, solicitando aos demais a melhor seleção do que é exposto no Yahoo!Grupos do CID.

Outra ferramenta monitorada foi a comunidade do CID do site de relacionamento Orkut. Esta comunidade, criada em 2005, contava com 169 membros até agosto de 2008. Como mencionado anteriormente, a comunidade possui um fórum de discussão, dividido em tópicos e agenda de eventos.

As informações postadas nestes dois recursos, embora possuíssem em muitos casos caráter acadêmico (como, por exemplo, a divulgação de congressos da área e de outros interesses comuns de alguns membros da comunidade), não possuíam necessariamente informações que proporcionassem o crescimento acadêmico e profissional dos usuários. Em outras palavras, é possível afirmar que estas ferramentas, mesmo sendo utilizadas por uma grande maioria dos alunos do curso, não têm seu potencial pedagógico como auxilio aos estudos, devidamente explorado pelos usuários e mantenedores.

Vale lembrar que, por meio da participação na comunidade, os integrantes têm acesso direto aos perfis dos demais membros, estabelecendo assim uma comunicação direta, ou seja, um diálogo com um determinado usuário. Isto proporciona aos usuários uma extensão das suas relações pessoais, desenvolvidas agora em uma nova ambientação social, o espaço virtual. Ou, como lembra Zygmunt Bauman (2004, p. 81): "o advento da proximidade virtual torna as conexões humanas simultaneamente mais freqüentes e mais banais, mais intensas e mais breves.".

\section{CONSIDERAÇÕES FINAIS}

Os dados obtidos e as observações realizadas no decorrer da pesquisa acerca da relação tecnologia/ educação enfocada a partir do comportamento de usuários dos alunos do CID permitem-nos algumas considerações.

Primeiramente, podemos dizer que o aluno do CID tem a possibilidade de utilizar uma gama de sistemas informacionais na internet tanto para o auxílio durante a pesquisa acadêmica quanto para entretenimento pessoal. Porém, durante o uso de alguns sistemas descritos anteriormente como, por exemplo, o Yahoo!Grupos e o STOA, foram encontrados, na maioria dos casos, alguns problemas sua utilização pelos alunos. Esses problemas podem ter ocorrido por falta de instrução dos alunos no uso de ferramentas digitais, porque atualmente as ações de estímulo e a facilitação do uso da ferramenta não são suficientes para uma maior adesão dos alunos ao seu uso e aprimoramento. No caso da navegação dentro do sistema, como acontece no STOA, foi observado nas entrevistas com os alunos que a falta de aplicabilidade do sistema durante o andamento do curso é um dos principais entraves para o sucesso desse projeto. Assim, a falta de interesse observada, na hora da utilização da ferramenta, acontece porque o aluno não sabe exatamente como explorar as possibilidades que a ferramenta oferece.

Outra questão importante relaciona-se com a atuação dos moderadores. Podemos considerá-la tomando como exemplo o sistema Yahoo!Grupos, um dos mais utilizados pela maioria dos alunos entrevistados. Durante a monitoração da lista de discussão (lista de e-mails) mantida pelos alunos do CID, percebemos que o principal problema era um grande fluxo de mensagens que não eram de interesse 
comum, ou seja, mensagens que deveriam ser enviadas a determinados membros do grupo interessado no conteúdo da mensagem e não a todos os usuários do grupo de e-mail; era comum o envio de arquivos extensos, que muitas vezes causavam transtorno aos outros membros, que reclamam que suas caixas de mensagem estavam "sempre cheias", gerando discussões em torno de assuntos pouco relevantes (e que muitas vezes descambavam para ofensas pessoais).

A partir dos problemas apontados, salientamos como o papel do moderador é essencial, pois o mesmo tem o poder de estruturar e instruir os membros do grupo de e-mail ou de outro sistema virtual de interação a utilizar a ferramenta de forma correta, sem causar transtornos aos demais usuários. Outra responsabilidade do moderador é filtrar as mensagens enviadas ao grupo, divulgar os conteúdos disponíveis nas ferramentas e orientar os participantes para focar os assuntos discutidos dentro destas ferramentas de interação. Os moderadores atuam como mediadores da informação e exercem um papel importante no aprendizado dos usuários destas ferramentas digitais, pois é com a ajuda deles que os usuários desenvolverão competências cognitivas para situar-se em meio ao enorme fluxo de informação que essas ferramentas proporcionam.

Pudemos observar, dessa forma, que a lista eletrônica ou grupo de e-mail dentro de uma disciplina de graduação, ou até mesmo do próprio curso, como é o caso do CID, ajuda a criar uma conexão permanente entre os professores e os alunos. Torna-se possível levar informações importantes para o grupo, como orientações bibliográficas e de pesquisa, esclarecer dúvidas e trocar sugestões que não foram discutidas em sala e ainda oferecer a possibilidade de enviar textos e trabalhos via rede.

Em uma reportagem da revista eletrônica Espaço Aberto, o professor Luli Radfahrer, da Escola de Comunicação e Artes (ECA - USP), iá notava alguns dos problemas do sistema STOA, e observou algo que já havia sido mencionado nas entrevistas realizadas com os alunos do CID: a de que só usamos aquilo que sabemos usar. Por isso, ele acredita que o grupo que coordena o sistema deveria fazer uma melhor divulgação sobre suas possibilidades, para que as pessoas não tivessem receio de trabalhar com ele. Assim, se desde o primeiro dia de aula as ferramentas interativas forem apresentadas aos alunos, eles vão começar a demandar mais do sistema. Portanto, é necessário repensar criticamente a tendência de muitos dos alunos que vêm do ensino médio em serem "consumidores de aulas" passivos. Como argumenta o coordenador do projeto STOA, Ewout ter Haar, é preciso fornecer as possibilidades para o aluno ser um ator ativo em seu próprio processo de aprendizado, e as novas tecnologias digitais representam um ótimo meio para se fazer isso e deixar o fluxo de informação menos vertical.

Esta pesquisa confirmou que a internet favorece a construção cooperativa e o trabalho conjunto virtual entre professores e alunos, e destes entre si - mas ela não determina totalmente a natureza desse trabalho, nem garante automaticamente seu êxito. Podemos hoje participar de uma pesquisa em tempo real, de um projeto entre vários grupos e de uma investigação sobre assuntos de interesse do grupo e problemas da atualidade. Uma das formas mais acessíveis para trabalhar colaborativamente é criar uma página dos alunos, como um espaço virtual de referência, onde se constrói conhecimentos e é colocado o que acontece de mais importante no curso (textos, endereços eletrônicos, as análises e as pesquisas). Isto pode ser feito através de um site provisório, grupos de e-mail, como o grupo do CID no Yahoo!Grupos, ou por sistemas digitais oferecidos pela própria universidade, como é o caso do STOA. O fundamental é combinar o que os alunos podem fazer de melhor em sala de aula, como conhecerem-se e motivarem-se, com o que podem fazer a distância, que é se comunicar quando for necessário e também acessar materiais disponíveis na hora em que acharem conveniente.

O que parece importante é trabalhar integrando as dinâmicas de ensino tradicionais com as inovadoras, a escrita com o audiovisual, o texto seqüencial com o hipertexto, o encontro presencial com o virtual.

Dessa forma, o que muda no papel do professor? Muda a relação de espaço, tempo e comunicação com os alunos. $\bigcirc$ espaço de trocas aumenta da sala de aula para o virtual. $\bigcirc$ tempo de enviar ou receber informações amplia-se para qualquer dia da semana. O processo de comunicação acontece na sala de aula, no e-mail, nos sistemas colaborativos. É um papel que combina alguns momentos do professor convencional, com boas aulas expositivas, com momentos em que seu papel está mais próximo do gerente de pesquisa, do estimulador de busca, do coordenador dos 
resultados. É um papel de animação e coordenação muito mais flexível e constante, que exige muita atenção, sensibilidade, intuição e domínio tecnológico. Portanto, o papel do professor e de sua mediação pedagógica no processo de aprendizagem também entra em discussão, como salientado pelos alunos nas entrevistas.

que se observou especificamente em relação ao curso referenciado nessa pesquisa (mas que acreditamos poder ser estendido aos demais cursos de ensino superior na área de Humanas), é que o uso de tecnologia no processo de aprendizagem não é tão comum, e nem sempre sua aplicação é a mais adequada. Este quadro começa a mudar, entretanto, pois há uma maior abertura na academia para a formação das competências pedagógicas dos professores universitários, que são de importância estratégica na sua atuação docente e na aprendizagem de seus alunos. É interessante observar que esses profissionais são incentivados tanto a buscar novas metodologias de aula, como também a discutir seus papéis como professores e a maneira como se relacionam com seus alunos em aula e mediante a interação aluno/professor/alunos a partir das ferramentas digitais. Por outro lado, embora esse seja um discurso que se dissemina no meio acadêmico, nem sempre é acompanhado de ações e recursos (humanos, econômicos, estruturais) que, de fato, o viabilizem na prática. Assimilar as mudanças do ensino presencial decorrentes das tecnologias digitais não é fácil, já que caminhamos para formas de gestão menos centralizadas, mais flexíveis e integradas. Nesta integração do presencial e do virtual haverá uma maior participação de todos os agentes do processo: professores e alunos, mas também os pais e a comunidade, no gerenciamento, nas atividades, nos rumos de cada instituição escolar. Hoje, as instituições de ensino, principalmente as universidades, passam por um processo conturbado de reorganização, onde os interesses das partes envolvidas nem sempre coincidem, gerando inevitáveis debates e conflitos.

O uso da internet ou de ferramentas digitais na educação apresenta, portanto, suas dificuldades. Alguns alunos não aceitam facilmente essa mudança na forma de ensinar e aprender, pois estão acostumados a um modelo mais tradicional de aprendizagem, na função de receptores passivos que recebem conteúdos prontos do professor, e esperam que ele continue passando seus conhecimentos presencialmente - como no tradicional modelo "o professor fala e os alunos escutam". Isto pode estar ocorrendo com alguns dos alunos pesquisados, pois como observado nas entrevistas, quando colocados diante da utilização de um sistema virtual de apoio das disciplinas, poucos tiveram interesse em desenvolver suas habilidades dentro do sistema proposto em aula, não dando assim continuidade ao uso da ferramenta, como aconteceu com o STOA.

Outra questão acerca da utilização da internet no ensino é a facilidade de dispersão que ela proporciona. Muitos alunos se perdem no emaranhado de possibilidades de navegação. Não procuram o que foi combinado, deixando-se arrastar para áreas de interesse pessoal. O pressuposto é que o conhecimento se constrói ativamente, nos processos de filtragem, seleção, comparação, avaliação, síntese e contextualização do que é mais relevante e significativo. Entretanto, percebe-se como é fácil, no processo de navegação, perder tempo com informações pouco significativas, ficando na superficialidade dos assuntos, sem aprofundá-los, sem integrá-los num referencial teórico consistente.

Dentro do contexto exposto nessa pesquisa, pode-se inferir que os processos de comunicação tendem a ser mais participativos e as relações aluno/ professor e aluno/alunos mais abertas e interativas. Deve-se valorizar, nesse sentido, uma proposta de uma educação tecnológica, que é diferente de uma educação técnica, pensada apenas como treinamento para o uso de equipamentos, como observa Neil Postman. Para ele, os problemas que as escolas não podem solucionar sem computadores também não saberão solucionar com eles, especialmente dentro de uma perspectiva que prega que a tecnologia seja uma solução por si mesma. Segundo Postman, "atualmente, quase todos os roteiros que descrevem os usos de computadores levam as crianças a resolverem problemas sozinhas". (POSTMAN, 2002, p. 49) $\mathrm{Na}$ sua perspectiva, as escolas nunca se preocuparam essencialmente com a aprendizagem individualizada, mas com a criação de um ambiente no qual a interação entre os indivíduos fossem valorizadas, onde seus interesses particulares não se sobrepusessem aos interesses do coletivo. De outro modo, quando Pierre Lévy fala a respeito da inteligência coletiva - "o estabelecimento de uma sinergia entre competências, recursos e projetos, a construção e manutenção 
dinâmicas de memória em comum, a ativação de modos de cooperação flexíveis e transversais, a distribuição coordenada dos centros de decisão" -, é necessário considerar que o ciberespaço por si só não determina automaticamente o desenvolvimento da inteligência coletiva, apenas fornece a esta inteligência um ambiente propício do ponto de vista tecnológico (LÉVY, 1999, p. 28). Sem os valores da colaboração e da sociabilidade desenvolvido nas escolas, essas potencialidades dificilmente se realizarão.

Obviamente as dificuldades do ensino presencial não serão resolvidas com o ensino virtual. Dentro desta perspectiva, integrar os dois modelos nos faz rever, ampliar e modificar muitas formas de ensinar e aprender. O contato presencial é importante em momentos decisivos, no conhecimento interpessoal, na criação de elos de confiança e afeto. Conectados, podemos realizar trocas mais rápidas, cômodas e práticas, o que economiza tempo, um dos bens mais preciosos nesta "Sociedade da Informação". Buscar a síntese dos dois modelos de comunicação, o presencial e o virtual, valorizando o melhor de cada um deles, parece ser a melhor opção. Concluindo, considerando o contexto do advento da economia globalizada e a forte influência dos avanços dos meios de comunicação e dos recursos de informática, aliados à discussão acerca da mudança

\section{REFERÊNCIAS}

ABRANTES, T. Rede virtual uspiana. Revista Espaço Aberto, n.88, 2008. Disponível em: <http://www.usp.br/espacoaberto/arquivo/2008/espaco88fev/0capa.html >. Acesso em: 8 fev. 2008.

ALMEIDA, M.A. A gaiola de chips: apontamentos sobre tecnologia, sociabilidade e cultura na sociedade da informação. Revista Em Questão, n. 1 1, v. 1, p. 13-34, 2005.

CASTELLS, M. A era da informação: economia, sociedade e cultura. 2 v. São Paulo, Rio de Janeiro: Paz e Terra, 1999.

CASTELLS, M. Internet e sociedade em rede. In: MORAES, Denis de (Org.) Por uma outra comunicação: mídia, mundialização cultural e poder. Rio de Janeiro: Record, 2003. p.255-287.

CERNY, R.Z. Educação à distância mais aprendizagem aberta. In: BELLONI, M.L. (Org.) A formação na sociedade do espetáculo. São Paulo: Loyola, 2002. p. 1 19-168. (Coleção Tendências).

FIGUEIREDO, N.M. Paradigmas modernos da Ciência da Informação. São Paulo: Pólis, 1999. de paradigma da ciência, há cada vez menos lugar nas universidades para um ensino que se caracterize por uma prática pedagógica conservadora, repetitiva e acrítica, pois na "Sociedade da Informação" todos nós estamos reaprendendo a conhecer, a nos comunicar, a ensinar. Estamos aprendendo também a combinar o elemento humano e o tecnológico, integrando o individual, o grupal e o social. É claro que para isto acontecer os alunos não precisam somente das ferramentas, mas necessitam do auxilio, instrução e incentivo para saber como usá-las, para que usá-las e quando usá-las. Neste ponto é que os professores e as instituições de ensino têm um forte papel mediador a desempenhar: desenvolver e divulgar os sistemas digitais, integrando-os criativa e interativamente às suas estruturas de ensino. No decorrer da pesquisa, observamos que as inovações tecnológicas e a internet descortinam possibilidades de constituição de novos perfis societários, em que os novos meios de comunicação e interação via rede apontam mudanças de comportamentos e novas perspectivas nos modos de ensinar e aprender. Entretanto, essa possibilidade ainda encontra-se desigualmente acessível aos sujeitos. Cabe à Ciência da Informação refletir sobre essa desigualdade e as formas de superá-la, para produzir conhecimento relevante para a sociedade.
LÉVY, P. Cibercultura. São Paulo: Ed. 34, 1999.

POSTMAN, N. O fim da educação: redefinindo o valor da escola. Rio de Janeiro: Graphia, 2002.

PRIMO, A. Interação mediada por computador: comunicação, cibercultura, cognição. Porto Alegre: Sulina, 2007.

RAFINHA 2.0 Vídeo, criação e direção de Gustavo Donda/TV1, color., 9:36 min., Disponível em: < http://www.youtube.com/ watch? $\mathrm{v}=\mathrm{UI} 2 \mathrm{~m} 5 \mathrm{kn} V \mathrm{rvg}>$. Acesso em: 8 fev. 2008.

SANTAELLA, L. Navegar no ciberespaço: o perfil cognitivo do leitor imersivo. São Paulo: Paulus, 2004.

SPYER, J. Conectado: o que a internet fez com você e o que você pode fazer com ela. Rio de Janeiro: Jorge Zahar, 2007.

WOLTON, D. Internet, e depois: uma teoria crítica das novas mídias. Porto Alegre: Sulina, 2003. 
